\title{
Description of a Recovery Model in Rabbits for the Study of the Late Phase of Liver Ischemia-Reperfusion Injury
}

\author{
ATHINA G. MANTELOU ${ }^{1}$, ARGYRO ZACHARIOUDAKI ${ }^{2}$, GEORGE PAPPAS-GOGOS ${ }^{1}$, APOSTOLOS PAPALOIS ${ }^{2,3}$, \\ ALEXANDRA PAPOUDOU-BAI ${ }^{4}$, ANNA GOUSSIA ${ }^{4}$ and GEORGIOS K. GLANTZOUNIS ${ }^{1}$ \\ ${ }^{1}$ Department of Surgery, University Hospital of Ioannina and School of Medicine, \\ University of Ioannina, Ioannina, Greece; \\ ${ }^{2}$ Experimental, Educational and Research Center ELPEN, Athens, Greece; \\ ${ }^{3}$ European University Cyprus, School of Medicine, Nicosia, Cyprus; \\ ${ }^{4}$ Department of Pathology, Ioannina University Hospital and School of Medicine, \\ University of Ioannina, Ioannina, Greece
}

\begin{abstract}
Aim: Description of an anesthetic recovery model with endotracheal intubation in rabbits which provides metabolic stability for the study of the late phase of liver ischemia/reperfusion (I/R) injury. Materials and Methods: Two groups of New Zealand rabbits, $n=7$ in each, were used: Ischemia/reperfusion $(I / R)$ group $(45 \mathrm{~min}$ of partial liver ischemia/reperfusion) and no intervention (sham) group. Blood alanine aminotransferase, lactate, $\mathrm{pH}$ values, mean arterial pressure and $\mathrm{pCO}_{2}$ were calculated at baseline, and at 2 and 24 h post reperfusion. Tissue samples from left (ischemic) and right (non-ischemic) liver lobes were examined at 2 and $24 \mathrm{~h}$ after reperfusion. Results: The I/R group presented significantly higher levels of alanine aminotransferase $(p=0.001)$ at 2 and $24 h$, and of lactate $(p=0.016)$ at $2 h$ post reperfusion. No differences were documented for $\mathrm{pH}$, mean arterial pressure and $\mathrm{pCO}_{2}$. Histological exanimation revealed significant injury at $24 \mathrm{~h}$ post reperfusion for the $I / R$ group. Conclusion: This anesthetic recovery model permitted avoidance of hypoxia and respiratory acidosis, allowing the study of the late phase of $I / R$ injury.
\end{abstract}

The amelioration of liver ischemia-reperfusion (I/R) injury is very important in different clinical settings such as in liver

This article is freely accessible online.

Correspondence to: Georgios K. Glantzounis, MD, Ph.D., FEBS, Professor of Surgery and Transplantation, Head of HPB Unit, Department of Surgery, School of Medicine, University of Ioannina, 45 110, Ioannina, Greece. E-mail: gglantzounis@uoi.gr

Key Words: Ischemia-reperfusion, liver, rabbit, anesthesia, intubation, recovery. resections for hepatic neoplasms, liver transplantation, hemorrhagic shock, and low-flow cardiothoracic surgery. Liver I/R injury has two phases: early $(<4 \mathrm{~h})$ and late (4-48 $\mathrm{h})$. The early phase is characterized by the production of reactive oxygen species (ROS), which have direct hepatotoxic effects, and by activation of endothelial cells, which release inflammatory mediators. The late phase is characterized by a cellular phase involving the migration and activation of neutrophils, CD $4^{+}$T-lymphocytes, and platelets into the liver (1).

The importance of the study of the late phase of liver I/R lies in the significance of the reactions that take place and their consequences. Indeed, although ROS which are produced during the initial phase provoke hepatocellular injury, ROS produced by activated neutrophils in the late phase are mainly responsible for the most direct injury to hepatocytes (2). Indeed, the damage produced to the liver during the late phase is more severe compared to the early stage. Recruited neutrophils and hepatocytes, which are attracted by chemokines released from sinusoidal endothelial cells, produce ROS and proteases. The diffusion of ROS into the cytoplasm of liver cells causes dysfunction of the mitochondrial membranes and cellular apoptosis, whereas proteases destroy the basement membrane and extracellular matrix (3).

In order to study the late phase of liver I/R injury, a longterm experiment $(>8 \mathrm{~h})$ under general anesthesia, or a recovery experiment is required. In the field of hepatic $I / R$ injury, albeit animals such as mice and rats can be easily handled for experimental research purposes, rabbits have several advantages (4). The main advantage over the use of rats is that they allow blood withdrawal at different time points, with maintenance of metabolic stability, given that the induction of liver ischemia causes significant metabolic alterations particularly in acid-base balance (5). However, 
rabbits are very sensitive animals and intubation is very difficult for anatomical reasons. The anatomy of the upper airway of the rabbit, with its large incisors, voluminous tongue, restricted mandibular mobility and narrow oropharynx, contributes to the high degree of failure in intubating these animal (4, 6-10). Furthermore, rabbits tend to develop laryngospasm during handling, which can lead to failure of intubation or laryngeal injury $(4,8,10,11)$.

Moreover, the application of liver ischemia during such experiments produces metabolic acidosis and for this reason a recovery experiment is challenging $(12,13)$. Although previous studies have shown the use of the rabbits in the study of liver I/R, to the best of our knowledge, a general anesthesia model with endotracheal intubation and recovery has not been implemented before in the study of the late phase of liver I/R in rabbits (14-23).

The purpose of this study was to present an anesthetic model of general anesthesia with endotracheal intubation in rabbits that can be implemented in the study of the late phase of liver I/R. The model should offer stability of the basic physiological parameters of the animals and allow safe recovery and follow-up for $24 \mathrm{~h}$.

\section{Materials and Methods}

Before the main project was carried out, laboratory staff were trained in intubating euthanized rabbits, following the completion of different experimental protocols, conducted in the same laboratory. A pilot study was subsequently carried out, in which three animals were used in order to resolve technical issues.

New Zealand White rabbits weighting 2.8 to $3.2 \mathrm{~kg}$ were used. The study was carried out at the Experimental, Educational and Research Center ELPEN which conforms to the European Directive 2010/63/EU for the Protection of Animals used for Scientific Purposes. The study was approved by the Experimental, Educational and Research Center ELPEN Project Evaluation Committee and licensed by the Veterinary Authorities of Athens Region (license no: 7492 20/11/2014).

All rabbits (Trompetas Rabbit Farms, Nea Dafni, Megara, Greece) were housed individually in a stainless-steel cage system under standard environmental conditions $\left(20-21^{\circ} \mathrm{C}, 45 \%\right.$ to $65 \%$ relative humidity, $12 \mathrm{~h}$ light-dark cycle) and were allowed to acclimatize to the laboratory environment for 7 days. They had $a d$ libitum access to a fiber rabbit diet (12C Pezzulo; Nutrir ${ }^{\circledR}$, Eboli, Italy) and water, and were not fasted preoperatively.

Two groups of seven animals each were used. The animals subjected to general anesthesia and laparotomy-only constituted the sham group. The animals subjected to general anesthesia, laparotomy and $45 \mathrm{~min}$ of partial $(70 \%)$ hepatic ischemia constituted the I/R group. The duration of each phase (ischemia and reperfusion) was calculated for rabbits in the sham group in order to maintain an equal duration of anesthesia for both groups.

Blood samples were collected for the analysis of acid-base balance and liver injury at baseline, 2 and $24 \mathrm{~h}$ post reperfusion by measurement of $\mathrm{pH}$, lactate and alanine aminotransferase (ALT) values. Blood pressure and ventilation were assessed by monitoring of mean arterial pressure (MAP) and $\mathrm{pCO}_{2}$ at the same time points. Histological examination of the liver was performed by means of tissue samples from both left (ischemic) and right (non-ischemic) lobes at 2 and $24 \mathrm{~h}$ post reperfusion.

Anesthetic model. Drugs used for anesthesia and analgesia were thiopental sodium ( ${ }^{\circledR}$ Thiopental VUAB inj. plv.sol. $1.0 \mathrm{~g}$; VUAB Pharma a.s., Roztoky, Czech Republic) and sevoflurane ( ${ }^{\circledR}$ Sevorane, $100 \%$ w/w sevoflurane; AbbVie Pharmaceuticals S.A., Neo Iraklio, Greece), which was administered through a ventilator (Merlin Small Animal Ventilator; Vetronic, Abbotskerswell, Devon, UK) and a non-rebreathing anesthetic circuit. For analgesia butorphanol $\left({ }^{\circledR}\right.$ Dolorex $10 \mathrm{mg} / \mathrm{ml}$, Intervet Hellas, Alimos, Greece) was administered.

The animals were anesthetized with thiopental sodium (30-50 $\mathrm{mg} / \mathrm{kg}$ ), given intravenously through the marginal ear vein. The anesthetic was administered slowly, in small boluses, to avoid respiratory arrest. Adequate depth of anesthesia was determined by the degree of mandibular relaxation. Subsequently, the animal was positioned in sternal recumbency and its head supported by the index and thumb finger of the assistant, placed at the angles of the mandible and the cervical spine of the animal was extended. After opening the mouth and slightly pulling the tongue out of the oral cavity by means of a gauze, an otoscope was advanced into the oral cavity and pharynx of the rabbit. Then, by further extending the head, the vocal cords were visualized. At this point, a flexible guide was carefully advanced through the otoscope into the trachea. The otoscope was then withdrawn, and an endotracheal tube $(3.0 \mathrm{~mm}$ ID, uncuffed) was advanced over the guide with gentle rotary movements (Figure 1). The correct position of the tube was confirmed by the condensation of the tube and feeling of air coming out of the tube during expiration. Additional, indirect signs of the correct position of the tube were coughing and crossing of the rabbit's front limbs. The whole procedure lasted 2 to 3 minutes. Throughout the procedure, maintenance of the spontaneous breathing of the animal was continuously controlled. During the endotracheal intubation of the rabbits, there was no clinically detectable laryngospasm.

The animal was then carefully placed in a lateral position and the tube secured at $14 \mathrm{~cm}$ from the incisors, a length corresponding to a position above the division of the trachea. At this point, $0.5 \mathrm{mg} / \mathrm{kg}$ butorphanol was administered intravenously, the endotracheal tube was connected to a ventilator and mechanical ventilation at a tidal volume of $35-40 \mathrm{ml}$ and a rate of 42 respirations/min was initiated. The correct position of the tube was again assessed by auscultation to check for bilateral breath sounds. Anesthesia was maintained with sevoflurane $3-4 \%$ and a fraction of inspired oxygen $\left(\mathrm{FiO}_{2}\right)$ of $70 \%$. The transducer was calibrated with the zero level set at the animal's middle chest. The animal was then positioned in the supine position and shaved. Rabbits were kept on a warming blanket, temperature was monitored via a rectal probe and maintained between 38 and $38.5^{\circ} \mathrm{C}$. Continuous monitoring was performed with a multiparameter monitor, displaying heart rate, electrocardiogram, blood pressure, oximetry and temperature.

Recovery of animals was uneventful, with spontaneous breathing returning a few minutes after discontinuation of the anesthetic gas. Once the animals were able to lift their head and swallow, the endotracheal tube was removed. Rabbits remained in the laboratory with an oxygen face mask until they were able to hold a sternal position, a second dose of butorphanol $(0.5 \mathrm{mg} / \mathrm{kg})$ was administered 

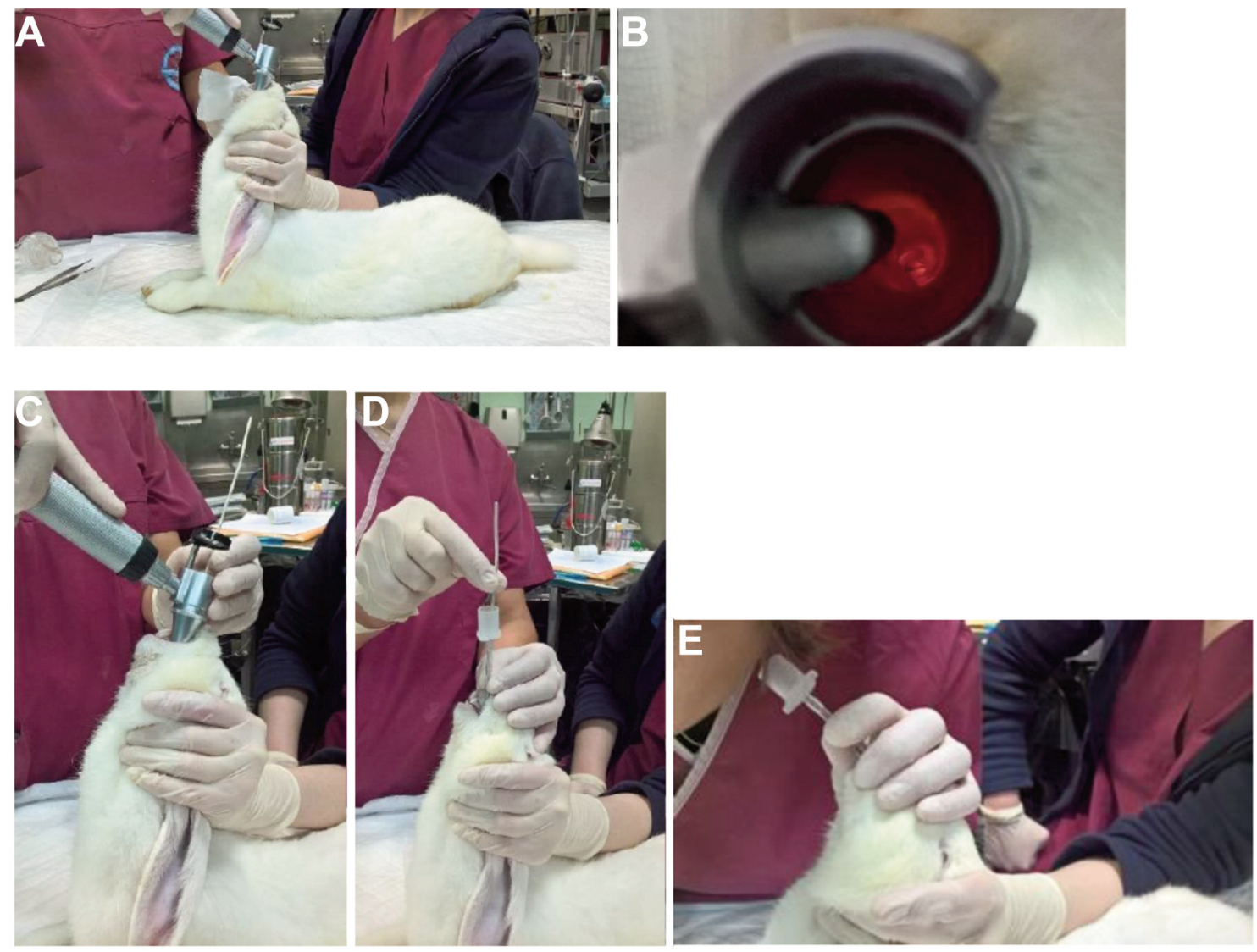

Figure 1. Orotracheal intubation of rabbits with the use of an otoscope and a flexible guide, presented step by step (A-E), as applied during the present study.

subcutaneously, the venous and arterial catheters were removed and animals were then transferred to their cages, where they again had free access to food and water. Butorphanol doses were repeated at regular time intervals.

Liver ischemia-reperfusion model. Laparotomy was performed through a median incision. After dissection of the falciform ligament, the afferent vessels to the median and left lateral lobes were visualized by everting the hepatic lobes upwards. Ischemia was induced by clamping the vascular pedicles of the median and left lobes of the liver for $45 \mathrm{~min}$. Splanchnic congestion was not observed because of partial occlusion of the hepatic portal inflow. Anesthesia was maintained for $2 \mathrm{~h}$ after reperfusion, at which time point blood and tissue samples from liver lobes subjected to ischemia were collected.

At $24 \mathrm{~h}$ post reperfusion, the animals were anesthetized according to the same protocol, blood samples were drawn, and a second laparotomy through the previous median incision followed. Tissue samples from both left (ischemic) and right (non-ischemic) lobes were collected. At the end of the experiment animals were euthanized.

Histological evaluation. Light microscopic evaluation of liver I/R injury was performed on hematoxylin and eosin-stained sections of liver biopsies in both groups. Parameters of hepatocellular injury were evaluated with a semi-quantitative score. Sinusoidal dilatation, congestion, hepatocellular vacuolization, mitosis and apoptosis were scored according to a 4-level scale (0: absent, 1 : mild $<5 \%, 2$ : moderate $5-10 \%, 3$ : severe $>10 \%$ ), the presence of polymorphonuclear (PMN) leukocytes (in and outside sinusoids) was scored according to a 4-level scale (0: none, 1: 1-5 PMNs, 2: 5-20 PMNs, 3: >20 PMNs) according to the number of PMNs observed and necrosis was scored based on the observed percentage of necrosis ( $0: 0 \%, 5$ points: $<30 \%$, 10 points: $30-60 \%, 20$ points: $>60 \%$ ). All parameters were evaluated in five high-power fields $(400 \times$ objective) per section.

Statistical analysis. Data are presented as medians (with interquartile range). For the comparison of the parameters between the two groups, Mann-Whitney $U$-test was used. Friedman test was used for the comparison of values amongst the three time points. Data analysis was performed using statistical software IBM SPSS Statistics 23.0 IBM, Armonk, NY, USA). Statistical significance was defined as differences with $p<0.05$.

\section{Results}

Ventilation. Values of $\mathrm{pCO}_{2}$ at baseline and $24 \mathrm{~h}$ post reperfusion, which were measured before induction of 


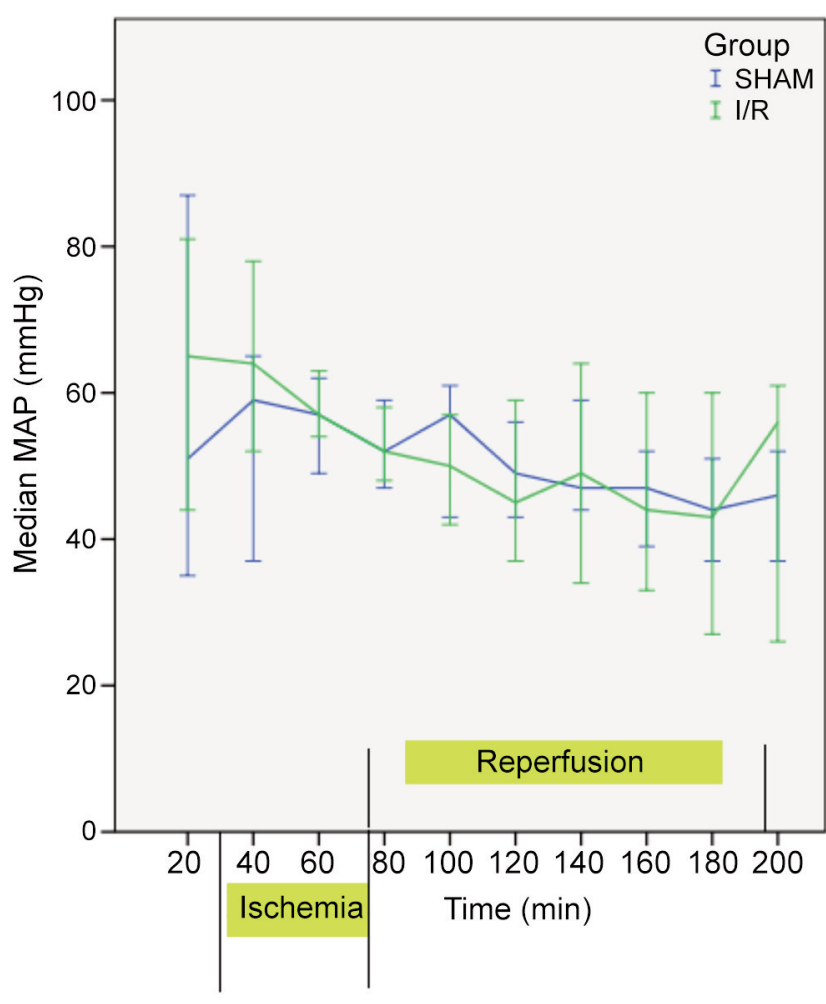

Figure 2. Median values of mean arterial pressure (MAP) during the experiment for the ischemia-reperfusion $(I / R)$ and sham-operated groups. Bars represent the $95 \%$ confidence interval.

anesthesia, were lower compared to values $2 \mathrm{~h}$ after reperfusion for both groups, but none of these differences was statistically significant (Friedman test). Median $\mathrm{pCO}_{2}$ values at baseline [35 (38-28) $\mathrm{mmHg}$ and $37(42-35) \mathrm{mm}$ $\mathrm{Hg}], 2 \mathrm{~h}$ post-reperfusion before recovery [40 (45-34) $\mathrm{mm}$ $\mathrm{Hg}$ and $41(55-36) \mathrm{mm} \mathrm{Hg}$ ] and at $24 \mathrm{~h}$ post-reperfusion [31 $(37-27) \mathrm{mm} \mathrm{Hg}$ and $31(36-27) \mathrm{mm} \mathrm{Hg}$ for the sham and the I/R groups, respectively, did not differ significantly.

Blood pressure. Rabbits remained hemodynamically stable during the entire liver I/R procedure, despite a fall in MAP observed after ischemia induction. At the end of the ischemic period, MAP measurements did not significantly differ between the two groups. Similarly, at $2 \mathrm{~h}$ post reperfusion, MAP did not differ significantly between the two groups, although rabbits in the IR group presented higher MAP compared to the sham group. MAP in both groups was lower after $2 \mathrm{~h}$ of reperfusion (or general anesthesia for the sham group) compared to the values at baseline (Figure 2).

$p H$. Values at baseline were 7.47 (7.51-7.43) and 7.48 (7.607.34) for the sham and I/R group, respectively, while $\mathrm{pH}$ decreased at $2 \mathrm{~h}$ post-reperfusion before recovery to 7.43

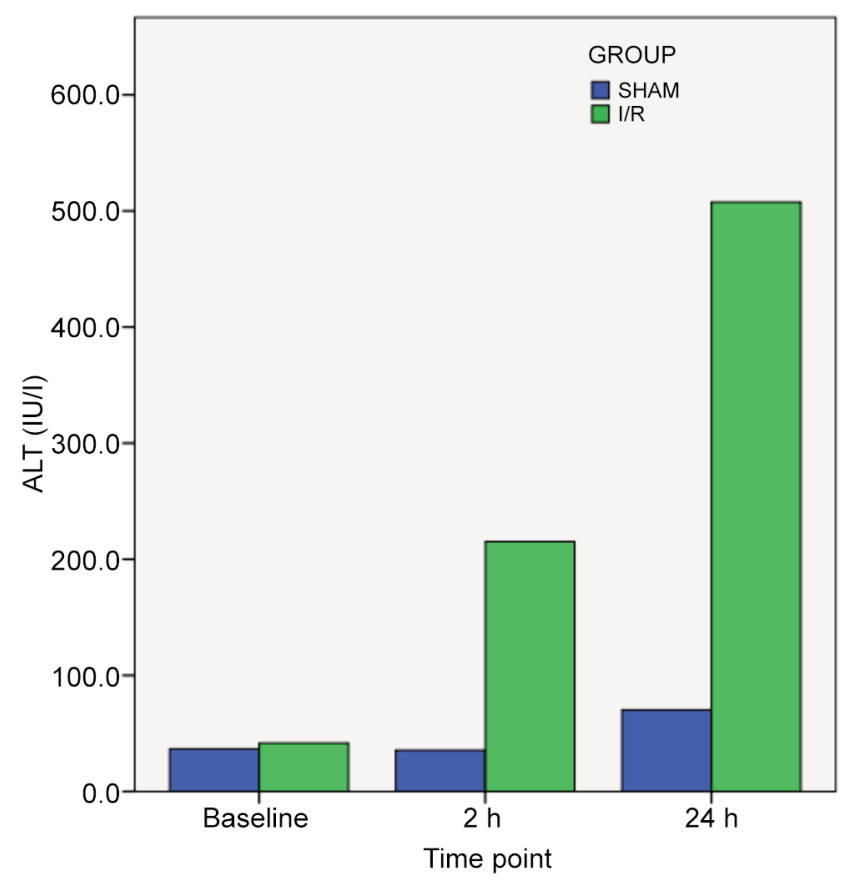

Figure 3. Serum alanine aminotransferase (ALT) levels for the sham and ischemia-reperfusion $(I / R)$ groups at baseline and at 2 and $24 \mathrm{~h}$ after reperfusion. Sham $v s . I / R$ at baseline, $p>0.05$; sham $v s . I / R$ at 2 and $24 h, p=0.001$ for both comparisons. Bars represent the $95 \%$ confidence interval.

(7.46-7.33) and 7.41 (7.51-7.36) for the sham and $\mathrm{I} / \mathrm{R}$ groups, respectively. At $24 \mathrm{~h}$ post reperfusion and before induction of anesthesia, $\mathrm{pH}$ values were 7.43 (7.47-7.35) and 7.43 (7.50-7.33) for the sham and I/R groups, respectively. There was no statistically significant difference between the two groups at the different time points or between different timepoints within the two groups.

Lactate. Lactate concentration did not differ significantly between the sham and I/R groups at baseline [1.59 (2.22$0.96)$ and $3.16(4.09-2.4)$ respectively] and $24 \mathrm{~h}$ after reperfusion $\left[\begin{array}{ll}2.59 & (3.56-1.17)\end{array}\right]$ and 2 (2.68-0.85) respectively]. At $2 \mathrm{~h}$ post-reperfusion we recorded significantly higher values $(p=0.026)$ for the I/R group [2.1 (3.17-1.91)] in comparison to values for the sham group [(1.78 (2.01-1.31)].

Liver injury parameters. At baseline, these was no statistically significant difference between the two groups. Forty-five minutes of partial hepatic ischemia led to a rise of the biochemical markers of liver injury. ALT levels at 2 and $24 \mathrm{~h}$ post-reperfusion differing significantly between the two groups ( $p=0.001$ for both comparisons). ALT levels at 24 

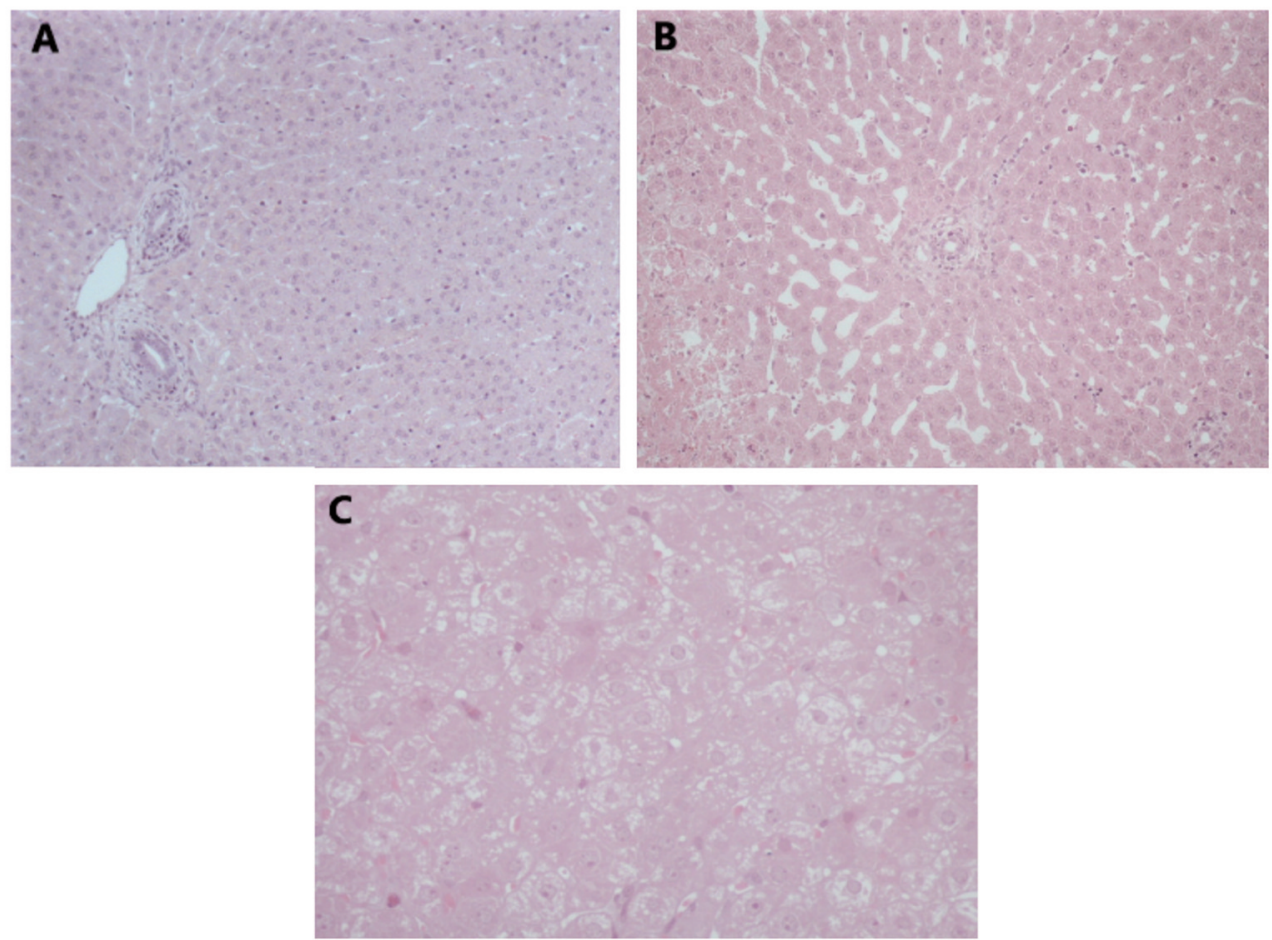

Figure 4. Histology of liver slices $24 \mathrm{~h}$ after no ischemia for the sham group (A) and $24 \mathrm{~h}$ after 45 min of partial hepatic ischemia for the ischemiareperfusion $(I / R)$ group $(B$ and $C)$. A: No histological alteration was apparent $(\times 100)$. B: Moderate sinusoidal dilatation was evident $(\times 200)$. C: Moderate hepatocellular vacuolization (ballooning) was clearly visible $(\times 400)$. Total mean score for hepatocellular injury (as described in the Materials and Methods) at $24 \mathrm{~h}$ after reperfusion was significantly higher in the I/R group compared with the sham group $(p=0.011)$.

hours for the I/R group were significantly higher from those at baseline and $2 \mathrm{~h}$ after reperfusion, $p=0.023$ and 0.010 , respectively (Figure 3).

Histology. The total mean score for liver injury was significantly higher in the I/R group compared with the sham group at $2 \mathrm{~h}$ post reperfusion [8 (11-8) vs. 2 (3-1), respectively, $p=0.004$ ] (Figure 4). Liver injury was significantly greater at $24 \mathrm{~h}$ post reperfusion for the I/R group compared with the sham group [12 (19-5) vs. 3 (3-2), $p=0.011]$.

Scores for tissue samples collected at $24 \mathrm{~h}$ post-reperfusion from the right liver lobe, where no ischemia was induced, were not significantly higher for the I/R group compared to the sham group [3 (3-2) vs. 2 (2-2), respectively].

\section{Discussion}

This article aimed to describe a rabbit model of general anesthesia with endotracheal intubation and mechanical ventilation for the study of liver I/R injury, with emphasis on the late phase. It has been found that liver damage is more severe in the late stage of I/R than in the early stage due to excessive ROS and proteases production (3). In order to study the late phase of this phenomenon, the ideal anesthetic model should offer hemodynamic stability, preventing hypoxia and acidosis. In addition, it should allow animal recovery and follow-up for $24 \mathrm{~h}$. To the best of our knowledge, such a model has not been implemented before in the study of the late phase of liver I/R in rabbits.

Our results confirm that this model allowed close hemodynamic monitoring and avoidance of hypoxia and respiratory acidosis. Animal recovery was uneventful and partial liver ischemia of $45 \mathrm{~min}$, although leading to significant liver injury, was not associated with mortality within the $24 \mathrm{~h}$ post reperfusion period, allowing the study of the late phase of I/R injury.

Rabbits were selected for this study because they allow easy placement of probes and blood withdrawal at different time points. The anatomy of the rabbit liver with separate lobes makes the identification of vascular elements and selective interruption of blood supply easier. Since the study of the late phase of liver $\mathrm{I} / \mathrm{R}$ and need for animal recovery were the main criteria that led to the selection of this model, the ideal anesthetic model, apart from being safe, had to be as minimally invasive and as atraumatic as possible, tailored to the available laboratory equipment, ensuring consistency with the principles of the Three "Rs" (Replacement, Reduction and Refinement) $(5,9,24)$. 
Previous studies have shown that the anesthetic procedure used and, specifically, the respiratory support provided influence oxygenation and ventilation of experimental animals. Heijnen et al. used endotracheal intubation and mechanical ventilation to achieve efficient gas exchange or spontaneous breathing via a face mask to induce respiratory acidosis in rats. Moreover, they showed that acidosis, and hypoxia may alter the extent of hepatic I/R injury (25).

Tracheostomy, cricothyroidotomy or retrograde intubation were rejected for our study as they are invasive, increasing the risk of apnea, traumatic lesions of the trachea, infections and causing significant postoperative stress, which may affect the results, as well as animal recovery (9).

Endotracheal intubation has been widely described in rabbits used for scientific purposes but, to the best of our knowledge, not in a similar liver I/R model $(7,26,27)$. Mongardon et al. compared I/R injury under normothermic and hypothermic conditions by cross-clamping the aorta in intubated and ventilated rabbits (28). Models of liver I/R applying various ischemia and reperfusion times have been described in literature, using ventilation through tracheostomy, face mask or no ventilatory support $(17,20$, $29,30)$. Guo et al. used no airway or ventilatory support and allowed the recovery of rabbits up to $48 \mathrm{~h}$ post-reperfusion after inducing hepatic ischemia for $60 \mathrm{~min}$ (23, 31). Langdale et al. used ketamine anesthesia to apply $45 \mathrm{~min}$ of liver ischemia and allowed recovery of rabbits for $24 \mathrm{~h}$ (32). However, the information provided about the anesthetic protocols, I/R times and parameters measured to assess liver I/R by both authors mentioned above do not allow comparison with the present study.

Numerous previous reports in literature describe the complications of orotracheal intubation in rabbits. Complications of endotracheal intubation include cuff-induced injury, edema and lesions of the oropharyngeal soft tissue, glottis and trachea, or even perforation of the trachea, caused by the tip of the tube or laryngoscope, obstruction of the endotracheal tube, bronchial intubation, inadvertent extubation and laryngospasm $(4,7,9-11)$. Risk factors that increase the incidence of the above-mentioned complications include inadequate depth of anesthesia, repeated attempts to intubate the trachea, inappropriate size of the endotracheal tube, and movement of the endotracheal tube while changing the position of the animal or during the surgical procedure $(4,9,11,33,34)$. Mechanical ventilation may also be accompanied by various complications or adverse effects, such as barotrauma, increased ventilation/perfusion ratio and air-trapping because of intrinsic positive end-expiratory pressure (6).

In the present study, prevention of barotrauma was attempted by achieving adequate depth of thiopental anesthesia and by administration of butorphanol to adequately suppress spontaneous breathing prior to the connection with the ventilator, as described in the section on the anesthetic model.
Therefore, standardizing the anesthetic method by choosing the proper anesthetic and analgesic drugs, administering appropriate doses to achieve adequate anesthetic depth, properly positioning/handling of the animal to minimize attempts and time needed for intubation in combination with the correct ventilation parameters lead to less complications and distress for the animal $(4,9,33)$.

The 45 min of partial (70\%) liver ischemia resulted in a marked rise in serum transaminase ALT at 2 and $24 \mathrm{~h}$ of reperfusion, indicating significant liver injury. The animals remained hemodynamically stable despite a fall in MAP during anesthesia. This fact can be attributed to the effect of the inhalational anesthetic and lack of painful stimuli after induction of ischemia. For the I/R group, stimulation of the sympathetic nervous system as an initial response to reperfusion injury, may have contributed to the higher values of MAP, compared to the sham group. Ischemia of the liver is probably responsible for the higher values of lactate at 2 $\mathrm{h}$ after reperfusion for the I/R group. The described duration of ischemia also allowed the survival of the animals and the study of the late phase of I/R of the liver. Partial liver ischemia has advantages over total liver ischemia, as rabbits cannot tolerate total hepatic ischemia beyond $25 \mathrm{~min}$ (35).

In conclusion, we described an anesthetic model of general anesthesia and endotracheal intubation in rabbits applied in a model for the study of the late phase of liver I/R with 24-h follow-up, and which offers hemodynamical and metabolic stability. Mechanical ventilation ensured hemodynamic stability during the entire liver I/R procedure, preventing hypoxemia and respiratory acidosis (hypercapnia) due to insufficient ventilation.

Standardization of anesthetic models used in liver I/R studies is crucial for comparison of animal models. Respiratory support by mechanical ventilation of the animals, controls and stabilizes physiological parameters that affect I/R injury which cannot be controlled with other anesthetic models. This model can be applied safely for the study of different therapeutic strategies which aim to ameliorate the deleterious effects of the late phase of reperfusion injury.

Limitations of the study. Close monitoring of the animals was restricted to the duration of general anesthesia $(3.5 \mathrm{~h})$. Concerning complications of endotracheal intubation and mechanical ventilation, the 24-h follow-up may not be adequate. Complications such as respiratory distress or infection secondary to traumatic tracheal lesions and tracheal stenosis may present at a later timepoint $(11,34)$.

\section{Conflicts of Interest}

The Authors report no proprietary or commercial interest in any product mentioned or concept discussed in this article. 


\section{Authors' Contributions}

M.A., Z.A. and G.G. designed the model and carried out the experiment; M.A. processed the experimental data, performed the analysis, drafted the article and designed the figures; G-P and G.G. revised critically the article; P.A. and G.G. supervised the project; P-B.A. and G.A. carried out the histological analysis.

All Authors provided critical feedback and helped shape the research, analysis and article.

\section{Acknowledgements}

The Authors are pleased to acknowledge the contribution of the personnel of the Experimental, Educational and Research Center of ELPEN Pharmaceuticals (Athens, Greece), namely: Maria Karamperi, Eleftheria Karampela, Kalliopi Tsarea, Stergios Gerakis, Evripidis Gerakis, Antonios Karaiskos and Nikolaos Psychalakis in the performance of the experiments.

This work was funded as Scholarship by the Experimental, Educational and Research Center ELPEN Pharmaceuticals, Athens, Greece.

\section{References}

1 Cannistrà M, Ruggiero M, Zullo A, Gallelli G, Serafini S, Maria M, Naso A, Grande R, Serra R and Nardo B: Hepatic ischemia reperfusion injury: A systematic review of literature and the role of current drugs and biomarkers. Int J Surg 33 Suppl 1: S57-S70, 2016. PMID: 27255130. DOI: 10.1016/j.ijsu.2016.05.050

2 Konishi $\mathrm{T}$ and Lentsch $\mathrm{AB}$ : Hepatic ischemia/reperfusion: Mechanisms of tissue injury, repair, and regeneration. Gene Expr 17(4): 277-287, 2017. PMID: 28893351. DOI: 10.3727/ $105221617 X 15042750874156$

3 Wang H, Xi Z, Deng L, Pan Y, He K and Xia Q: Macrophage polarization and liver ischemia-reperfusion injury. Int J Med Sci 18(5): 1104-1113, 2021. PMID: 33526969. DOI: 10.7150/ijms. 52691

4 Morgan TJ and Glowaski MM: Teaching a new method of rabbit intubation. J Am Assoc Lab Anim Sci 46(3): 32-36, 2007. PMID: 17487950

5 Parasuraman S, Raveendran R and Kesavan R: Blood sample collection in small laboratory animals. J Pharmacol Pharmacother 1(2): 87-93, 2010. PMID: 21350616. DOI 10.4103/0976-500X.72350

6 Gografe SI, Wilson JS, Johnson BL, Rushing G, Bowser A, Parker JL and Cornelius CE: Successful management of longterm general anesthesia in rabbits used as an animal model of human disease. Contemp Top Lab Anim Sci 42(2): 16-19, 2003. PMID: 19757619

7 Balbinotto RP, Trindade MR, Meyer FS, Muller AL, Rosa Ad Jr, Nunes AG and da Silva R: Anesthetic protocol for videolaparoscopic surgery in rabbits. Acta Cir Bras 25(1): 121-125, 2010. PMID: 20126900. DOI: 10.1590/s0102-86502010000100024

8 Tran HS, Puc MM, Tran JL, Del Rossi AJ and Hewitt CW: A method of endoscopic endotracheal intubation in rabbits. Lab Anim 35(3): 249-252, 2001. PMID: 11459409. DOI: 10.1258/ 0023677011911705

9 Falcão SC, Pereira Junior JR and Coelho AR: Technique of blind tracheal intubation in rabbits (Oryctolagus cuniculi) supported by previous maneuver of esophageal cannulization. Acta Cir Bras 26(5): 352-356, 2011. PMID: 21952657. DOI: 10.1590/ s0102-86502011000500005

10 Stephens Devalle JM: Successful management of rabbit anesthesia through the use of nasotracheal intubation. J Am Assoc Lab Anim Sci 48(2): 166-170, 2009. PMID: 19383213.

11 Phaneuf LR, Barker S, Groleau MA and Turner PV: Tracheal injury after endotracheal intubation and anesthesia in rabbits. J Am Assoc Lab Anim Sci 45(6): 67-72, 2006. PMID: 17089996.

12 Guan LY, Fu PY, Li PD, Li ZN, Liu HY, Xin MG and Li W: Mechanisms of hepatic ischemia-reperfusion injury and protective effects of nitric oxide. World J Gastrointest Surg 6(7): 122-128, 2014. PMID: 25068009. DOI: 10.4240/wjgs.v6.i7.122

13 Wu MY, Yiang GT, Liao WT, Tsai AP, Cheng YL, Cheng PW, Li CY and Li CJ: Current mechanistic concepts in ischemia and reperfusion injury. Cell Physiol Biochem 46(4): 1650-1667, 2018. PMID: 29694958. DOI: 10.1159/000489241

14 Glantzounis GK, Yang W, Koti RS, Mikhailidis DP, Seifalian AM and Davidson BR: Continuous infusion of $\mathrm{N}$-acetylcysteine reduces liver warm ischaemia-reperfusion injury. Br J Surg 91(10): 1330-1339, 2004. PMID: 15376207. DOI: 10.1002/bjs.4694

15 Glantzounis GK, Sheth H, Thompson C, Hafez TS, Kanoria S, Pamecha V, Davies S, Mikhailidis DP, Seifalian AM and Davidson BR: Acute limb ischemia caused by femoral arterial line induces remote liver injury in a rabbit model of liver ischemia/reperfusion injury. Angiology 60(5): 554-561, 2009. PMID: 19625265. DOI: 10.1177/0003319709338176

16 Glantzounis GK, Rocks SA, Sheth H, Knight I, Salacinski HJ, Davidson BR, Winyard PG and Seifalian AM: Formation and role of plasma S-nitrosothiols in liver ischemia-reperfusion injury. Free Radic Biol Med 42(6): 882-892, 2007. PMID: 17320770. DOI: 10.1016/j.freeradbiomed.2006.12.020

17 Fusai G, Glantzounis GK, Hafez T, Yang W, Quaglia A, Sheth H, Kanoria S, Parkes H, Seifalian A and Davidson BR: NAcetylcysteine ameliorates the late phase of liver ischaemia/reperfusion injury in the rabbit with hepatic steatosis. Clin Sci (Lond) 109(5): 465-473, 2005. PMID: 15982189. DOI: 10.1042/CS20050081

18 Tapuria N, Junnarkar S, Abu-Amara M, Fuller B, Seifalian AM and Davidson BR: Modulation of microcirculatory changes in the late phase of hepatic ischaemia-reperfusion injury by remote ischaemic preconditioning. HPB (Oxford) 14(2): 87-97, 2012. PMID: 22221569. DOI: 10.1111/j.1477-2574.2011.00407.x

19 Li J, Jiang J, Chu Z, Zhang Y, Cai W, Zhu J, Grimm R and Ji Q: Multiparametric MRI evaluation of liposomal prostaglandins E1 intervention on hepatic warm ischemia-reperfusion injury in rabbits. J Magn Reson Imaging 52(1): 217-228, 2020. PMID: 31829483. DOI: $10.1002 /$ jmri.27022

20 Kanoria S, Glantzounis G, Quaglia A, Dinesh S, Fusai G, Davidson BR and Seifalian AM: Remote preconditioning improves hepatic oxygenation after ischaemia reperfusion injury. Transpl Int 25(7): 783-791, 2012. PMID: 22533545. DOI: 10.1111/j.1432-2277.2012.01481.x

21 Jiang J, Li J, Chu Z, Tao Z, Cai W, Zhu J, Grimm R and Ji Q: In vivo multiparametric magnetic resonance imaging study for differentiating the severity of hepatic warm ischemia-reperfusion injury in a rabbit model. Magn Reson Imaging 74: 105-112, 2020. PMID: 32931888. DOI: 10.1016/j.mri.2020.09.010

22 Yamada T, Nagata H, Kosugi S, Suzuki T, Morisaki H and Kotake Y: Interaction between anesthetic conditioning and 
ischemic preconditioning on metabolic function after hepatic ischemia-reperfusion in rabbits. J Anesth 32(4): 599-607, 2018. PMID: 29931389. DOI: 10.1007/s00540-018-2523-7

23 Guo CW, Shen SD, Zhang Y, Yi XL, Liang C and Luo W: Perfusion computed tomography evaluation of partial hepatic ischemia reperfusion in a rabbit model. Acad Radiol 18(10): 1311-1317, 2011. PMID: 21893297. DOI: 10.1016/j.acra. 2011.05 .012

24 Osborne NJ, Payne D and Newman ML: Journal editorial policies, animal welfare, and the 3Rs. Am J Bioeth 9(12): 5559, 2009. PMID: 20013503. DOI: 10.1080/15265160903318343

25 Heijnen BH, Elkhaloufi Y, Straatsburg IH and Van Gulik TM: Influence of acidosis and hypoxia on liver ischemia and reperfusion injury in an in vivo rat model. J Appl Physiol (1985) 93(1): 319-323, 2002. PMID: 12070220. DOI: 10.1152/ japplphysiol.01112.2001

26 Weinstein $\mathrm{CH}$, Fujimoto JL, Wishner RE and Newton PO: Anesthesia of six-week-old New Zealand White rabbits for thoracotomy. Contemp Top Lab Anim Sci 39(3): 19-22, 2000. PMID: 11178320.

27 Yershov AL, Jordan BS, Fudge JM and Dubick MA: Influence of the mode of ventilation on ketamine/xylazine requirements in rabbits. Vet Anaesth Analg 34(3): 157-163, 2007. PMID: 17444928. DOI: 10.1111/j.1467-2995.2006.00315.X

28 Mongardon N, Kohlhauer M, Lidouren F, Hauet T, Giraud S, Hutin A, Costes B, Barau C, Bruneval P, Micheau P, Cariou A, Dhonneur G, Berdeaux A, Ghaleh B and Tissier R: A brief period of hypothermia induced by total liquid ventilation decreases end-organ damage and multiorgan failure induced by aortic cross-clamping. Anesth Analg 123(3): 659-669, 2016. PMID: 27482772. DOI: 10.1213/ANE.0000000000001432

29 Chen H, Ma Y and Ying L: Effects of ginseng polysaccharides on hepatocellular energy metabolism in hepatic ischemia reperfusion injury in rabbits. Journal of Liver 01(02): 1000107, 2017. DOI: $10.4172 / 2167-0889.1000107$
30 Matsumoto T, Yamaguchi M, Kikuchi H, Nakano H, Midorikawa $\mathrm{T}$, Kumada $\mathrm{K}$ and Takeda M: Heparin reduces serum levels of endothelin-1 and hepatic ischemia reperfusion injury in rabbits. Surg Today 30(6): 523-525, 2000. PMID: 10883463. DOI: $10.1007 / \mathrm{s} 005950070119$

31 Guo CW, Shen SD, Zhang Y, Liang CH, Yi XL and Luo W: Determination of apparent diffusion coefficient to quantitatively study partial hepatic ischemia reperfusion injury in a rabbit model. Transplant Proc 43(5): 1474-1479, 2011. PMID: 21693220. DOI: 10.1016/j.transproceed.2011.01.183

32 Langdale LA, Kajikawa O, Frevert C and Liggitt HD: Sustained tolerance to lipopolysaccharide after liver ischemia-reperfusion injury. Shock 19(6): 553-558, 2003. PMID: 12785011. DOI: 10.1097/01 shk.0000055238.25446.64

33 Imai A, Eisele PH and Steffey EP: A new airway device for small laboratory animals. Lab Anim 39(1): 111-115, 2005. PMID: 15703132 . DOI: 10.1258/0023677052886484

34 Grint NJ, Sayers IR, Cecchi R, Harley R and Day MJ: Postanaesthetic tracheal strictures in three rabbits. Lab Anim 40(3): 301-308, 2006. PMID: 16803648. DOI: 10.1258/ 002367706777611415

35 Kanoria S, Glantzounis G, Jalan R, Davies NA, Seifalian AM, Williams R and Davidson BR: A model to study total hepatic ischemia-reperfusion injury. Transplant Proc 36(9): 2586-2589, 2004. PMID: 15621096. DOI: 10.1016/j.transproceed.2004. 10.031

Received August 23, 2021

Revised September 23, 2021 Accepted September 29, 2021 